\title{
Multiple urolithiases in pediatric acute lymphoblastic leukemia
}

\author{
Ayumi Fujishiro ${ }^{1}$, Ryosuke Matsuno ${ }^{2}$, Taichi Omachi', Takashi Yamazoe ${ }^{4}$, Mai Okano ${ }^{5}$, Kazunari Kaneko ${ }^{6}$ \\ From ${ }^{1}$ Specialist Trainee, ${ }^{2}$ Associate Professor, ${ }^{3,4,5}$ Assistant Professor, ${ }^{6}$ Professor, Department of Pediatrics, Kansai Medical University, Osaka, Japan
}

\begin{abstract}
Current study is a case report of a 5-year-old patient with T-cell acute lymphoblastic leukemia (ALL) and multiple urolithiasis. Complex factors, including glucocorticoid-induced hypercalciuria, fluid restriction for the syndrome of inappropriate secretion of antidiuretic hormone, and long-term bed rest, predispose children with ALL to develop urolithiasis. To prevent urinary urolithiasis formation, urinary calcium excretion should be monitored during chemotherapy and when administering glucocorticoids.
\end{abstract}

Keywords: Acute lymphoblastic leukemia, Glucocorticoid, Syndrome of inappropriate secretion of antidiuretic hormone, Urolithiasis

A cute lymphoblastic leukemia (ALL) is the most common malignancy in children. More than $80 \%$ of pediatric patients with ALL can be cured with current pediatric chemotherapeutic regimens, and the survival rate of ALL in high-income countries exceeds $90 \%$ [1,2]. However, various complications can occur during the treatment period. Urolithiasis is considered to be an extremely rare complication in pediatric ALL patients [3]. Current therapeutic regimens for ALL, consist of four important phases comprising remission induction, consolidation, re-induction, and maintenance. Typical induction and re-induction therapies include glucocorticoids, vincristine, L-asparaginase, and anthracycline [1]. A longer duration of glucocorticoid administration ( $>4$ weeks in induction therapy) can cause iatrogenic Cushing Syndrome [4]. An excess of glucocorticoids affects calcium metabolism and reduces tubular reabsorption of calcium followed by hypercalciuria [3,5]. Furthermore, long-term bed rest during induction therapy can stimulate bone decalcification and increase the risk of hypercalciuria $[3,6,7]$. Here, we report a child with T-cell ALL who developed multiple urolithiases associated with hypercalciuria caused by a combination of various factors.

\section{CASE PRESENTATION}

A previously healthy 5 -year-old Japanese boy presented with an ill complexion and low-grade fever $\left(37.0-37.5^{\circ} \mathrm{C}\right)$ to a hospital and was then referred to our institution. A blood examination showed leukocytosis $(40,400 / \mu \mathrm{L}$; blasts, $53.5 \%)$,

\section{Access this article online}

Received - 15 July 2021

Initial Review - 03 August 2021

Accepted - 06 September 2021

DOI: $10.32677 / \mathrm{IJCH} .2021 . v 08.109 .3032$ anemia $(8.0 \mathrm{~g} / \mathrm{dL})$, and thrombocytopenia $(45,000 / \mu \mathrm{L})$. Bone marrow aspiration showed $94.8 \%$ blasts of the nuclear cell count. Flow cytometry showed that the cells were CD4-, CD5-, CD7-, and CD8-positive. A chest X-ray showed a mediastinal mass of which histopathology of the biopsy specimen was consistent with infiltration of T-cell leukemia/lymphoma (immunohistochemistry showed positive stain for CD3, CD4, CD5, and CD7). Prednisolone pretreatment was started after diagnosing T-cell ALL 4 days after admission. On the $11^{\text {th }}$ day of admission, induction therapy with dexamethasone, vincristine, L-asparaginase, daunomycin, and intrathecal therapy was initiated. On the $15^{\text {th }}$ day of admission, mild hyponatremia (134 $\mathrm{mEq} / \mathrm{L}$ ) developed. In the absence of other possible causes for hyponatremia, such as diuretic use or cortisol deficiency, the patient was diagnosed as having the syndrome of inappropriate secretion of antidiuretic hormone (SIADH). This diagnosis was based on the laboratory findings of a decreased serum osmolality (275 $\mathrm{mOsm} / \mathrm{kg})$, increased urine osmolality (572 $\mathrm{mOsm} / \mathrm{kg})$, increased urine sodium concentration $(30 \mathrm{mEq} / \mathrm{L})$, and detectable plasma antidiuretic hormone $(0.6 \mathrm{pg} / \mathrm{mL})$. On the basis of the SIADH diagnosis, he was instructed to restrict fluid intake, which resulted in a considerable decrease in the daily urine volume (from approximately 2000 to $800 \mathrm{~mL}$ ). On the $25^{\text {th }}$ day of admission, the patient's abdominal colic with hematuria prompted us to perform ultrasound echography, which showed urolithiasis in his right ureter. Because of exacerbation of his colic, despite analgesics, further evaluation including abdominal computed tomography (CT) was performed on the $32^{\text {nd }}$ day of admission. CT showed multiple stones in the right pelvis and pyelectasis in the right ureter (Fig. 1a-d).

On the basis of presumptive diagnosis of multiple urolithiases caused by sustained fluid restriction for SIADH and long-term

Correspondence to: Kazunari Kaneko, 2-5-1 Shinmachi, Hirakata, Osaka, Japan. E-mail: kanekok@hirakata.kmu.ac.jp

(C) 2021 Creative Commons Attribution-NonCommercial 4.0 International License (CC BY-NC-ND 4.0). 

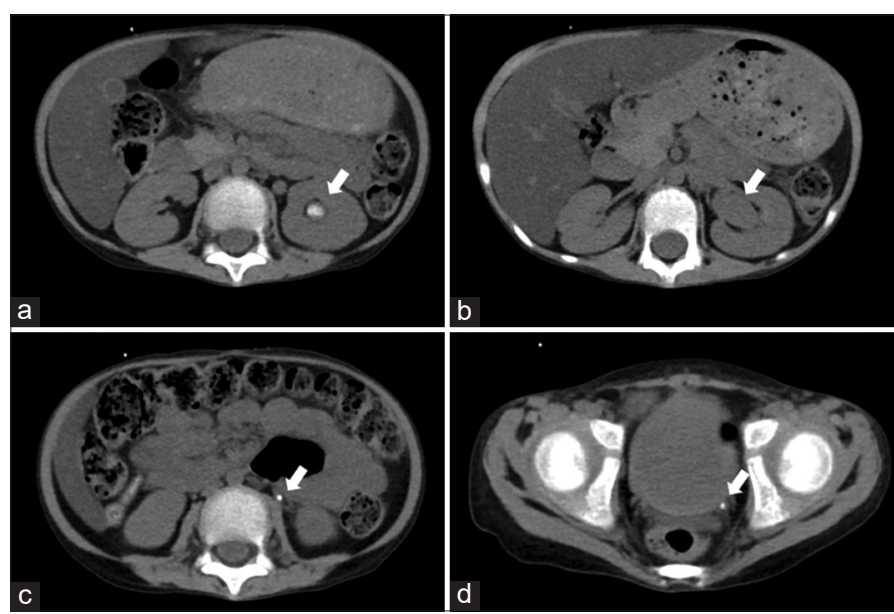

Figure 1: The computerized tomography (CT) of the kidneys and ureters on the $32^{\text {nd }}$ day of admission. (a, c, d) Multiple urolithiases in the right renal pelvis and ureter with right pyelectasis were found (indicated with an arrow). (b) The right renal pelvis dilatation is observed (indicated with an arrow)

bed rest, we initiated intravenous hydration to induce diuresis. During the following week, his abdominal pain was relieved in parallel with an increase in his urine volume, and ultrasound echography no longer detected urolithiasis on the $35^{\text {th }}$ day of admission.

Retrospective studies involving measurements of serial urinary calcium excretion and calculus analysis suggested that hypercalciuria caused by glucocorticoid administration was also involved in the formation of the kidney stones. Urinary calcium excretion as assessed by the calcium creatinine ratio $(\mathrm{mg} / \mathrm{mg} \mathrm{Cr}$ : reference value $<0.21[8])$ increased from 0.19 before therapy to 0.31 on day $17,0.54$ on day 22 , and 0.71 on day 29 .

Because of the possibility of involvement of glucocorticoidinduced hypercalciuria in urinary stone formation, aggressive intravenous hydration was applied when hypercalciuria developed during re-induction therapy including dexamethasone. As a result, recurrence of urolithiasis was not observed, despite the presence of hematuria.

\section{DISCUSSION}

Howard et al. reported that $0.9 \%$ of pediatric patients had ALL and urolithiasis in St. Jude Children's Hospital and the therapy including glucocorticoids, especially remission induction therapy, was represented as a risk factor [3]. This incidence is much higher than that in healthy children. The author also showed that $35 \%$ of patients had recurrent urolithiasis. In our report, re-induction therapy including dexamethasone could have been a trigger of hematuria associated with urolithiasis. This glucocorticoid-induced urolithiasis can be associated with hypercalciuria. Hori et al. reported a survey of hypercalciuria during pediatric ALL treatment in a single institution [9]. They showed a low frequency of urolithiasis (1/55 patients) and a high frequency of hypercalciuria (49/55 patients, $89 \%)$ during chemotherapy. They also showed that an increase in the urinary calcium creatinine ratio was associated with glucocorticoid use in induction and re-induction therapies. These findings suggested that pediatric patients with ALL develop treatment-related hypercalciuria more frequently than originally thought by pediatric oncologists. Additional factors of urolithiasis can easily be a trigger for onset. Taking into consideration that hypercalciuria is a risk factor for developing urolithiasis, urinary calcium excretion should be monitored during chemotherapy, particularly in patients with glucocorticoid-included regimens. Other possible predisposing factors for developing urolithiasis in the present case could have been concentrated urine due to a restriction of fluid intake for SIADH and an exacerbation of hypercalciuria due to immobilization by long-term bed rest.

Asians might be predisposed to developing SIADH following vincristine administration and its incidence is reported to be as high as $10 \%$ [10]. For the treatment of SIADH, restriction of fluid intake is essential, whereas forced diuresis by good hydration is important for preventing the formation of urolithiasis in the presence of hypercalciuria.

\section{CONCLUSION}

A high index of suspicion for urolithiasis is required in pediatric patients with leukemia while undergoing chemotherapy, even though this condition is uncommon in childhood. Risk factors for developing urolithiasis may include glucocorticoid-induced hypercalciuria, fluid restriction for SIADH, and long-term bed rest. Therefore, to prevent urolithiasis formation, moderate exercise in conjunction with monitoring urinary calcium excretion and daily urine volume are desirable during chemotherapy for pediatric patients with leukemia.

\section{ACKNOWLEDGMENT}

We thank Ellen Knapp, PhD, from Edanz (https://jp.edanz.com/ ac) for editing a draft of this manuscript.

\section{REFERENCES}

1. Inaba $\mathrm{H}$, Pui $\mathrm{CH}$. Advances in the diagnosis and treatment of pediatric acute lymphoblastic leukemia. J Clin Med 2021;10:1926.

2. Kato M, Manabe A. Treatment and biology of pediatric acute lymphoblastic leukemia. Pediatr Int 2018;60:4-12.

3. Howard SC, Kaplan SD, Razzouk BI, Rivera GK, Sandlund JT, Ribeiro RC, et al. Urolithiasis in pediatric patients with acute lymphoblastic leukemia. Leukemia 2003;17:541-6.

4. Alkhuder L, Mawlawi H. Infantile iatrogenic cushing syndrome due to topical steroids. Case Rep Pediatr 2019;2019:2652961.

5. Akkus Y, Bas VN, Yilmaz Z. Cushing syndrome induced by long term use of corticosteroids in the management of atopic dermatitis. Pediatr Endocrinol Diabetes Metab 2020;26:216-9.

6. Monga M, Macias B, Groppo E, Kostelec M, Hargens A. Renal stone risk in a simulated microgravity environment: Impact of treadmill exercise with 
lower body negative pressure. J Urol 2006;176:127-131.

7. Tamma G, Di Mise A, Ranieri M, Svelto M, Pisot R, Bilancio G, et al. A decrease in aquaporin 2 excretion is associated with bed rest induced high calciuria. J Transl Med 2014;12:133.

8. Pavlou M, Giapros V, Challa A, Chaliasos N, Siomou E. Does idiopathic hypercalciuria affect bone metabolism during childhood? A prospective case-control study. Pediatr Nephrol 2018;33:2321-8.

9. Hori D, Kobayashi R, Suzuki D, Kodama K, Yanagi M, Matsushima S, et al. A survey of hypercalciuria during chemotherapy in acute lymphoblastic leukemia. Pediatr Int 2021;63:923-8.

10. Seetharam S, Thankamony P, Gopakumar KG, Krishna KM. Higher incidence of syndrome of inappropriate antidiuretic hormone secretion during induction chemotherapy of acute lymphoblastic leukemia in indian children. Indian J Cancer 2019;56:320-4.

Funding: None; Conflicts of Interest: None Stated.

How to cite this article: Fujishiro A, Matsuno R, Omachi T, Yamazoe T, Okano M, Kaneko K. Multiple urolithiases in pediatric acute lymphoblastic leukemia. Indian J Child Health. 2021; 8(9):340-342. 